\title{
Incorporating Writing Into An Introductory Business And Economics Statistics Course: A Practical Approach
}

Cullen F. Goenner, University of North Dakota

Sean Michael Snaith, (E-mail: sean.snaith@ mail.business.und.edu), University of North Dakota

\begin{abstract}
Writing across the curriculum (WAC) has become a guiding principle at many institutions of higher education. Unfortunately for many students of economics and business the standard vehicles of WAC do not adequately prepare them for the type of writing appropriate for the audience they are expected to address upon graduation. We describe a method of implementing writing into the introductory statistics courses that are required by many programs in economics and business. This method addresses the shortcomings of the standard vehicles of WAC while at the same time providing instructors with a feasible solution to do so in light of the multiple constraints faced by many instructors of this type of course. (JEL A22)
\end{abstract}

\section{Introduction}

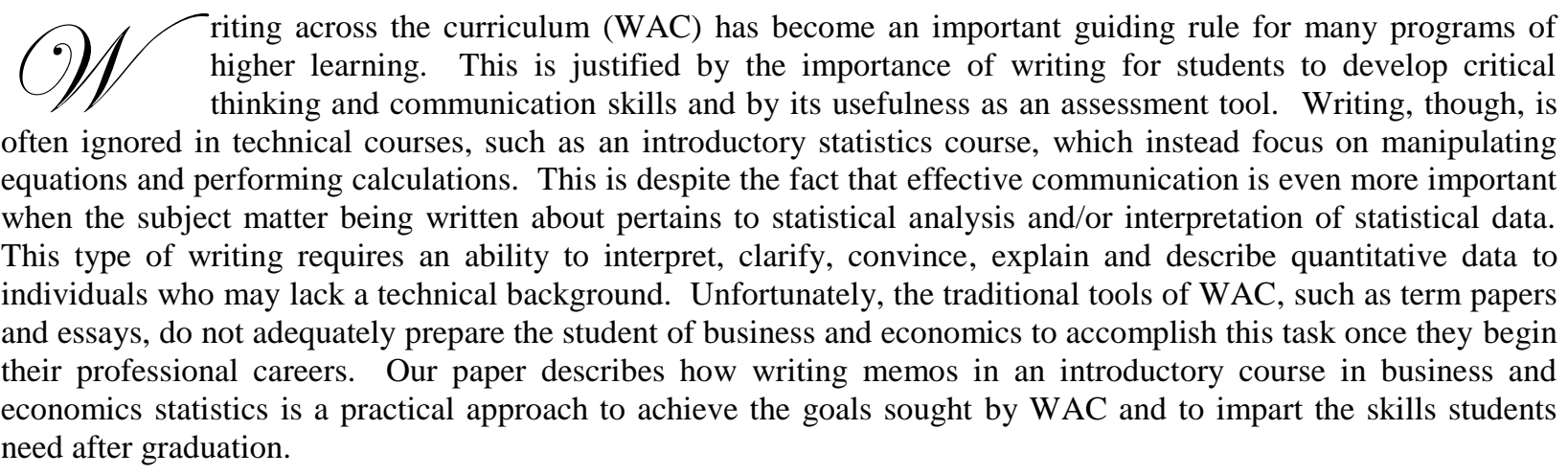

Memos represent a concise form of written communication that is commonly used in business and often directed to a general audience. The incorporation of memo writing assignments into an introductory statistics course achieves multiple goals. First, the student will become familiar with electronic retrieval of data and the use of software common to the business world. Second, applying the tools of statistical analysis using real world data reinforces the learning of the student (Hakim 2001) and promotes a deeper understanding of the use of such tools in business. Third, writing clear analysis of the results of statistical exercises deepens understanding and at the same time develops the skill of explaining technical and complex ideas to a general audience in a straightforward manner. Finally, this method is an excellent tool of assessment for the instructor, enabling the instructor to distinguish between students who simply "plug and chug" and those who have true understanding of the tools they are using. While other writing assignments may achieve these goals, the use of memos allows instructors, without resources such as lab sections and graders, to incorporate writing into introductory statistics curriculum without sacrificing scarce lecture time or other competing demands on the instructor's time. 


\section{Writing in an Introductory Statistics Course: Benefits and Challenges}

Writing across the curriculum has gained wide acceptance as an instrument that improves educational outcomes. WAC is a phrase coined in the late 1970's as a catchall description of the attempts by colleges and universities to extend the scope of student writing beyond the traditional confines of English departments. The emphasis on WAC stresses the importance of communication skills, critical thinking skills and faculty/student contact. Furthermore, WAC promotes problem solving, careful examination and evidentiary support of ideas, and the ability to incorporate and synthesize information.

Students of economics are expected to become proficient in six areas laid out by Hansen (2001). They include learning how to: 1 . access existing knowledge; 2 . display command of existing knowledge; 3 . interpret existing knowledge; 4. interpret and manipulate economic data; 5. apply existing knowledge; and 6. create new knowledge. The cognitive ability required to obtain each proficiency increases as the student progresses through this list. Thus an introductory course, such as business and economics statistics, Hansen (2001, p.233) notes, "would emphasize the lower proficiencies (1-3), with some attention to 4 and 5."

Students in introductory statistics courses would improve their ability to learn these five skills by applying the theories and formulas they learn in class to actual economic and business problems. The first skill they would gain is learning to find, understand the meaning of, and retrieve economic data. The second draws on the student's understanding of statistical theory, and asks that the student be able to explain the use of statistics to others. The third skill requires the student to be able to understand how statistics contribute to the interpretation of events. The fourth skill, which is essential to a course in statistics, is the ability to evaluate economic data and display one's findings using charts and tables. Students of introductory statistics obtain the fifth skill by applying the first four skills in written analyses of economic and business problems.

Unfortunately, far too often students of introductory statistics courses do not achieve these skills. A survey of economics majors who graduated from UNC Chapel Hill, cited by Salemi and Siegfried (1999, p.358), found "that the required statistics course focused too much on technical aspects of statistics and too little on practical skills (e.g., how to verify and evaluate data)." To obtain these practical skills students must be given assignments that not only require them to master the calculations taught in statistics, but also to master how statistics are used to analyze data and draw conclusions in business and economics. The use of writing assignments in statistics is an important means of achieving these goals. The assignments encourage students to learn interpretation (Beins, 1993), critical thinking (Smith, 1995), creativity and how to communicate more effectively (Radke-Sharpe, 1991).

Writing assignments not only improve educational outcomes and assessment but can also prepare students to apply these skills once they graduate and enter the workforce. Effective communication, particularly through the written word, is an essential skill for students of business and economics. This is true at all levels of the organization and in the variety of roles students may one day play within an organization. This ability becomes even more important when the subject of the communication involves statistical data, analysis, interpretation and insight. Simpson and Carroll (1999) surveyed graduates of economics from their institution regarding the role of writing in their primary occupations and the results highlight this point. Simpson and Carroll (1999, p. 405) quote a respondent who wrote, "One of the major complaints I have with some of my employees is that many of them with economics or business degrees (MBAs included) can handle the quantitative side but can't assimilate the data into understandable or verbal analysis form .... We miss business because they cannot communicate effectively with a client." A specific example of a firm stressing the ability to write is Toyota Manufacturing, USA, who expects employees to write one page reports whenever possible, using graphics as much as possible (Carnes, 1997). The ability to effectively communicate complex economic and statistical concepts using standard language and visual aids, such as charts and graphs, and in a manner that is understandable and devoid of unnecessary technical jargon, is indispensable to success.

WAC has been referred to as a "powerful instrument of thought" with a "unique value for learning" (Palmini, 1996). This reference is a truism, but as Palmini later points out, the traditional vehicles of WAC implementation; term papers, essay exam, and case analysis are directed to a professional audience, the professor, 
who has no compelling need for the information contained therein. The subsequent outcome of this strategy is students who are ill-prepared for professional writing, having been educated in the strategies required to write papers and these other traditional WAC vehicles. This training may have a purpose of its own, such as helping the student learn a particular concept or theory, but (Flowers, 1981) has called them both "inadequate" and a "liability" once the student leaves school. Memos and business letters are more likely to be the type of writing that students of business and economics will use after graduation. This form of writing is more concise and often directed to a diverse audience that lacks a technical background.

Ideally, there would be no limit to the amount of writing assignments the instructor could assign. In a small liberal arts college setting, the ability to design in-depth writing intensive courses may be more feasible (Simpson and Carroll, 1999). However, at medium and large sized institutions with different institutional missions, larger class sizes, higher research burdens and limited resources in terms of teaching assistants, this task becomes a delicate balancing act. Instructors are faced with the goal of achieving the Hansen (2001) proficiencies under these challenging constraints.

We have implemented a solution that may be an effective way to address the need to incorporate writing into a statistics course under these circumstances; the use of short writing assignments interspersed throughout the semester along with the usual lecture meetings. The short assignments we assign combine statistical analysis and writing in the form of business memos. Memos are concisely written documents that convey relevant information in a manner understandable to the target audience. They are a routine method of communication within and outside of the firm. The respondents in Simpson and Carroll's (1999) survey of their alumni indicated that $76 \%$ wrote memos on a daily/weekly basis and 59\% reported that the use of memos was very/extremely important to success in their occupation. Writing a memo forces the student to clearly and succinctly convey a point, substantiated by the application of statistical analysis. Furthermore, the focused nature of the memo enables the instructor to grade these assignments in a reasonable amount of time, even for the large size of many introductory statistics classes.

The use of memos in an introductory statistics course allows the instructor to achieve the goal of implementing writing across the curriculum while preparing the student for the demands that will be placed upon him or her after graduation. While this type of writing is not meant as a substitute for the more traditional forms, we believe that it addresses a particular need of students who are heading into the business world while at the same time reaping the benefits associated with writing. The method that we employed in implementing this project is discussed in the following section and a sample lesson is available from the authors upon request.

\section{A Feasible Approach to Implementing Writing: Memos}

We have identified approximately seven subject areas in the curriculum of the introductory statistics class that we wish to cover by the memo assignments. Each memo is a 1-2 page typewritten document accompanied by any necessary graphical or tabular data. The memos are designed to emphasize each of the topics. The goal of each assignment is three-pronged. First, we want the assignment to be a pedagogical tool helping the student to better understand the concept through learning-by-doing. Secondly, to ensure a deeper understanding of each concept, the student must write up the results of the project explaining them in the memo to a general audience in the hypothetical firm where they are an employee. This is a crucial aspect of the assignment since it has been said that one does not truly understand a topic until one is able to explain it to others. Lastly, the student must use spreadsheet and presentation software, which is an essential part of virtually all business environments, to prepare the memo.

The assignments are given to the students as though they have been handed down from their manager in the firm. Research (Becker, 1998; Carlson, 1999) has shown the importance of using real world examples to actively engage students in statistical analysis. As Becker (1998) notes, the justification for teaching introductory statistics outside the math department is to put statistical methods into the context that students of business and economics will face. In order to provide as realistic an experience as possible the students are required to turn in a finished product that is professionally done and presented. Evaluation of the assignments may vary from instructor to 
instructor, and depending upon other constraints, the instructor may want to include a feedback cycle to make the projects even more beneficial to the student.

An important aspect of using memo assignments to implement writing in an introductory statistics course is that these assignments do not require the instructor to allocate as much time as traditional vehicles of WAC require. Another possible method to help alleviate time constraints in larger classes is to have students work on the memo assignments in small groups, this adds the additional benefit to the student of developing team approaches to completing projects. These time saving features of the memo approach is particularly relevant to instructors of statistics at many institutions who are constrained by large class sizes, a lack of lab sections, and a lack of grading assistance. Helping to minimizing the effects of these constraints is the self contained design of our assignments.

Each assignment provides a series of clearly posed questions which require statistical analysis. These questions allow some interpretation, but are expected to generate relative uniformity to ease grading. In order to complete the assignment, students are provided with a site to retrieve the data, though some formatting may be required. Additionally, the instructor may want to plant some obvious errors in the raw data to ensure that students examine the data before conducting analysis. Along with the assignment the student is given a handout with step-bystep instructions on how to use the relevant features of the software programs they will need to complete the project. The software we use is Microsoft Excel and PowerPoint. While this software is somewhat limited in its capabilities, it is prevalent in business and is readily available to students. Using software that students are typically familiar with, while providing instructions in its use, allows us to avoid the use of scarce lecture time to teach the students how to use the software. Additionally, a handout is given at the beginning of the semester detailing the guidelines for writing memos. The handout discusses the preparation, organization, formatting and stylistic aspect of writing a memo. This insures all aspects of the projects do not require any use of classroom time.

An example of one such assignment given early in the semester to introduce the student both to the process of preparing memos and to give experience using several tools of descriptive statistics is as follows. This project is designed to give the student an introduction into the memo writing exercise, experience using basic descriptive statistics using Excel in the context of portfolio allocation decisions. The complete assignment and an example of a student write-up are included in the appendix.

\section{Conclusions}

We have discussed a practical method of implementing writing in introductory statistics courses for business and economic majors. This method tackles many of the difficulties that instructors face with the scarcity of resources available to support the inclusion of writing into their statistics classes. Large class sizes, the lack of support staff and obligations to pursue the professional research necessary for promotion and tenure make the task of including writing assignments a difficult proposition. Nonetheless, we feel the potential benefit to students makes an endeavor to incorporate these exercises a worthwhile use of limited time and resources.

Not only does this method adhere to the principles of writing across the curriculum but at the same time it provides the students with exercises that help them to better understand the tools of technical analysis they learn in statistics. Additionally it gives them experience writing using the vehicles and software they will be expected to know once they begin their careers.

\section{References}

1. Becker, William E. 1998. Engaging Students in Quantitative Analysis with Short Case Examples from the Academic and Popular Press. American Economic Association Papers and Proceedings v. 88 480-486.

2. Beins, Bernard C. 1993. Writing Assignments in Statistics Classes Encourage Students to Learn Interpretation. Teaching of Psychology v. 20 161-164.

3. Carlson, William L. 1999. A Case Method for Teaching Statistics. The Journal of Economic Education v. $3052-58$.

4. Carnes, L.W. 1997. Writing Expectations for Toyota Employees. Unpublished Interview. 
5. Flower, L.S. 1981. Communication Strategy in Professional Writing: Teaching a Rhetorical Case. In Courses, Components and Exercises in Technical Communication, ed. D.W. Stevenson. Urbana, Ill.: National Council of Teachers of English.

6. Hakim, S.A. 2001. Effect of Experiential Learning in Business Statistics. Journal of Education for Business. v. 22 95-98.

7. Hansen, W. Lee. 2001. Expected Proficiencies for Undergraduate Economics Majors. The Journal of Economic Education v. 32 231-242.

8. Palmini, Dennis J. 1996. Using Rhetorical Cases to Teach Writing Skills and Enhance Economic Learning. The Journal of Economic Education v. 27 205-216.

9. Radke-Sharpe, N. 1991. Writing As a Component of Statistics Education. The American Statistician v. 45 292-293.

10. Salemi, Michael K. and Siegfried, John J. 1999 The State of Economic Education American Economic Association Papers and Proceedings v. 89 no. 2 355-361.

11. Simpson, Murray S. and Carroll Shireen E. 1999 Assignments for a Writing-Intensive Economics Course. The Journal of Economic Education v. 30 402-410.

12. Smith, Paul C. 1995 Assessing Writing and Statistical Competence in Probability and Statistics. Teaching of Psychology v. 22 49-50.

13. Stromberg, Arnold J. and Ramanathan, Subartha. 1996. Easy Implementation of Writing in Introductory Statistics Courses. The American Statistician v. 50 159-163.

14. Walstad, William B. 2001 Improving Assessment in University Economics. The Journal of Economic Education v. 32 281-294.

15. Warner, C. Bruce and Meehan Anita M. 2001 Microsoft Excel ${ }^{\mathrm{TM}}$ As a Tool for Teaching Basic Statistics. Teaching of Psychology v. 28 295-298.

16. Wight, Jonathan B. 1999. Using Electronic Data Tools in Writing Assignments. The Journal of Economic Education v. 30 21-27.

\section{APPENDIX}

Economics 395

Introduction to Financial Economics

Dr. Statistics

Project \#0

\section{Goals}

1. In this project you will analyze financial data and learn how to prepare a business memo that explains your findings in a clear and concise manner.

2. You will use Excel to calculate several descriptive statistics including the average, standard deviation, correlation, and weighted average.

3. You will also use Excel to generate several types of charts; bar, line, and pie.

4. Understand the basics of choosing an asset allocation for a portfolio

\section{Analytical Component}

1. Download the data set project0.xls from the course web page, which contains data on small company stock, large company stock, long-term government bond, intermediate term government bond, and Treasury bill annual returns for the period 1926-1998.

2. Calculate the average, minimum, maximum, and standard deviation of returns for each of the five time series.

3. Generate a histogram for Long term government bonds using Excel's data analysis feature. Use bins in 5\% increments. Is the distribution bell shaped? Using the empirical rule that $95 \%$ of the data values lie within two standard deviations of the mean, calculate these values for long-term bond returns. 
4. Calculate the average, minimum, maximum, and standard deviation of the excess return for Small Stocks, Large Stocks, Long term bonds, and Intermediate term bonds above the Treasury bill rate.

5. Generate a "Risk vs. Excess Return" chart with annual excess return on the vertical axis and risk (annual std. dev.) on the horizontal axis for the four series. Thus you will have 4 points on a single chart.

6. Draw a line chart using Excel that displays annual returns for large company stocks and intermediate term government bonds. Use the Excel function correl to compute the correlation between large company stocks and intermediate term government bonds.

7. Calculate the weighted average returns for each of the six portfolios below and generate a pie chart that depicts each portfolio's composition. List each portfolio's average return in the chart title, i.e. Growth: Average Return $\mathrm{x} \%$.

\begin{tabular}{|l|c|c|c|}
\hline \multicolumn{1}{|c|}{ Portfolio Name } & $\begin{array}{c}\text { Large Company } \\
\text { Stocks }\end{array}$ & Interm. Govt. Bonds & T-Bills \\
\hline Growth & $80 \%$ & $20 \%$ & $0 \%$ \\
\hline Moderate Growth & $60 \%$ & $40 \%$ & $0 \%$ \\
\hline Balanced Growth & $50 \%$ & $50 \%$ & $0 \%$ \\
\hline Conservative & $40 \%$ & $60 \%$ & $0 \%$ \\
\hline Income & $20 \%$ & $80 \%$ & $0 \%$ \\
\hline Stability & $10 \%$ & $80 \%$ & $10 \%$ \\
\hline
\end{tabular}

\section{Writing Component}

You have just been hired as a financial planner in a local firm. Your first order of business is to prepare a sales pitch that will attract future clients. Your boss, Edward Jones, has asked you to prepare a brief overview of asset allocation that requires you to apply some of your statistics skills to historical financial data. In a business memo to your boss you are to outline the talking points that you will use in your discussion. These should include

1. What are the risks versus return features of the different asset classes? Discuss returns and their variability. Be sure to attach your risk vs. excess return chart.

2. What are the benefits to an investment portfolio from holding bonds and stocks rather than just one of these assets?

3. How to use historical market performances of portfolios to determine what is the right mix of asset classes?

Be sure to attach your pie charts that you generated.

Economics 395

Project 0 Sample Write Up

TO: Edward Jones

FROM: John Q. Student

DATE: July 25, 2003

SUBJECT: Talking points for asset allocation

I believe it is important to discuss with clients the concepts of risk versus return and diversification in allocating their assets. Across the three asset classes of stocks, bonds and cash we see varying levels of return as well as risk. Cash, represented by returns on T-bills, offered an annual historical return of $3.8 \%$ over the period 1926-1998, compared to long-term government bonds that returned 5.5\% and large company stocks that returned 
13\%. Variability in returns though also differs across asset classes. For instance, large company stocks had a worst one year return of $-45.6 \%$, while the worst one year return on long-term government bonds was $-7.4 \%$. The standard measure of risk, standard deviation of returns, also demonstrates this relation. Returns on large company stocks have a standard deviation of $20.3 \%$, while that of long term bonds is $8 \%$. Large company stocks offer higher returns than long term bonds, but also higher risk. In Table 1, I display the excess return of four assets relative to their risk.

Another important aspect of asset allocation is diversification. The goal is to spread the risk around by holding a mix of asset classes to reduce the volatility of the portfolio. A good year in one asset class may help to offset a poor year in another asset. Correlation of .15 in the returns of large company stocks and intermediate term bonds indicate that considerable risk reduction is possible from holding a portfolio of these two asset classes. To help clients determine the right mix of assets in their portfolio, I have generated a chart with six asset allocations along with their historical returns.

If you have any suggestions or questions please let me know.

Attached: Table 1: Risk versus Excess Return

Table 2: Finding the Right Mix

Table 1: Risk versus Excess Return

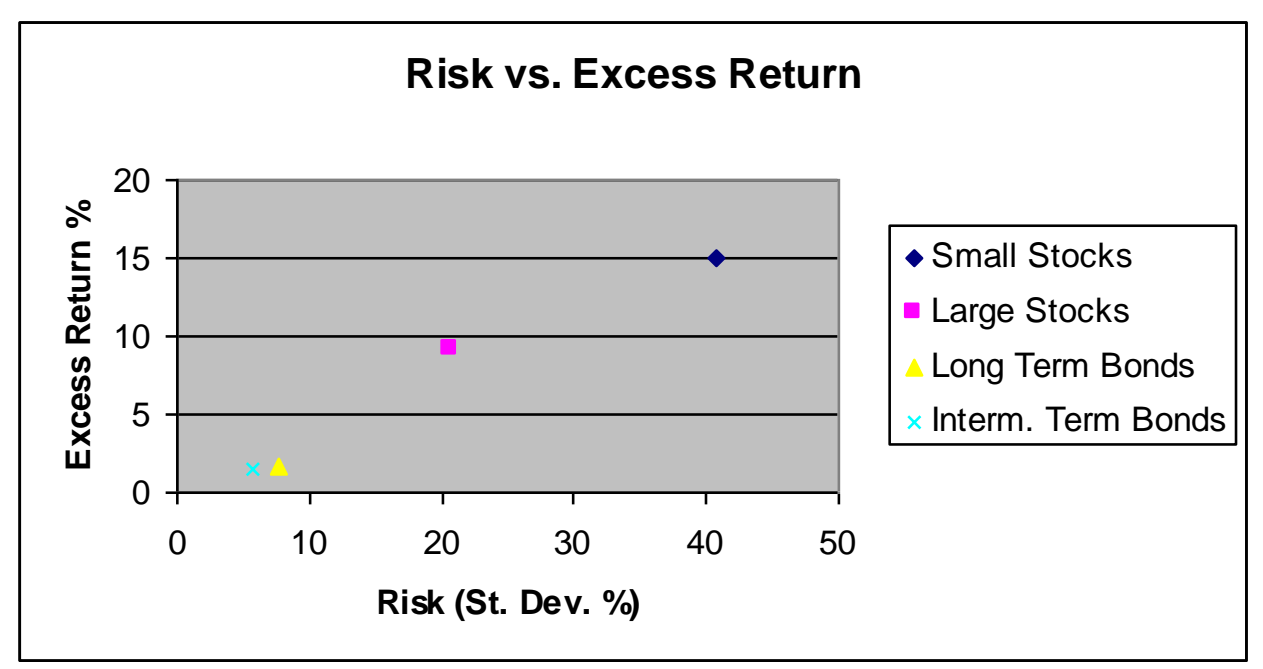


Table 2: Finding the Right Mix
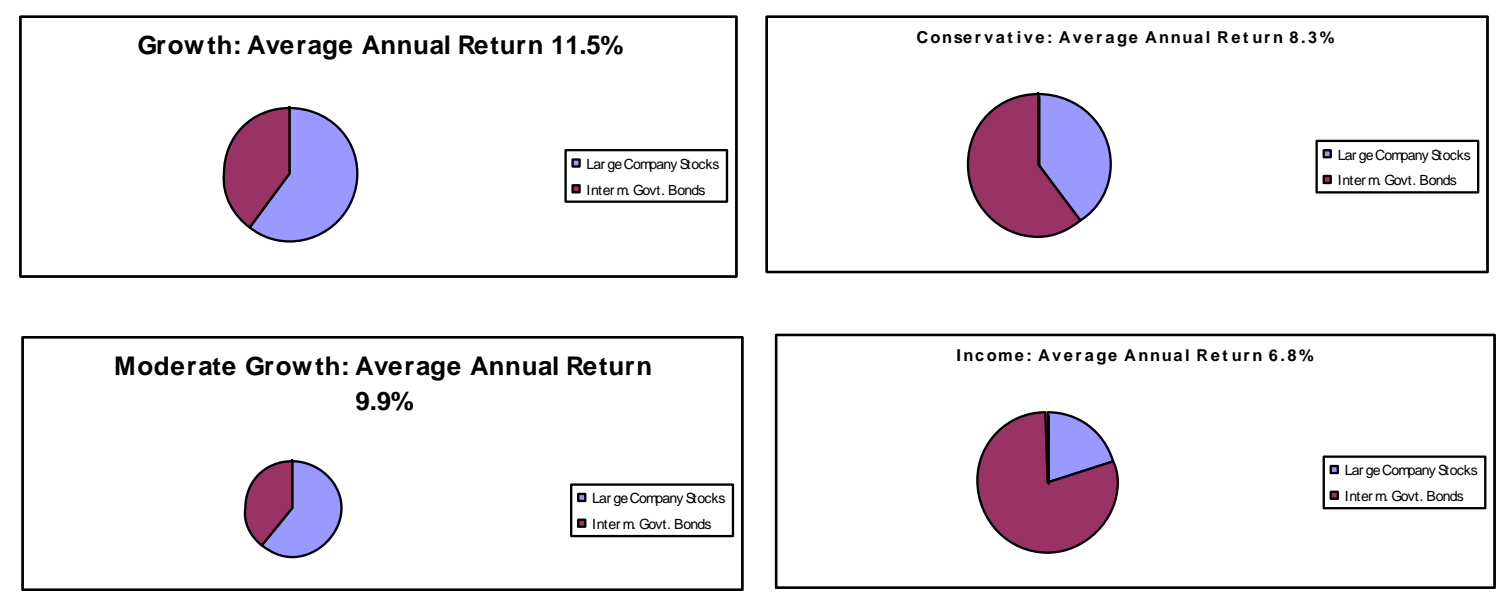

Balanced Growth: Average Annual Return $9.1 \%$
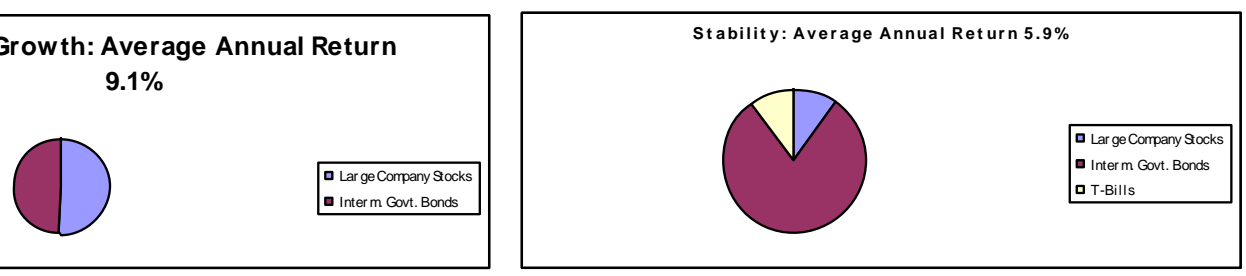

Notes 